\title{
Graphite contact phenomena developing in interaction with rare earth elements doped aluminum alloys studying.
}

\author{
* Panichkin A. V. \\ Institute of Metallurgy \\ and Ore Beneficiation \\ (IMOB) JSC, 050010, \\ Republic of Kazakhstan, \\ Almaty \\ Kenzhaliyev B. K. \\ Institute of Metallurgy \\ and Materials Science \\ of the Russian \\ Academy of Sciences, \\ Moscow, Russian \\ Federation.
}

\author{
Kshibekova B. B. \\ Institute of Metallurgy \\ and Ore Beneficiation \\ (IMOB) JSC, 050010,

$$
\text { Almaty }
$$ \\ NJSC "Kazakh \\ National Research \\ Technical University \\ named after K.I. \\ Satpayev, 050013, \\ Republic of Kazakhstan, \\ Almaty
}

Republic of Kazakhstan, Republic of Kazakhstan,

\begin{abstract}
Based on equilibrium in Al-REE and C-REE systems data, possibility of improvement carbon surface wetting with aluminum melt by their alloying with REE assumption is made. Aluminum melts MPG-6 graphite substrate flat surface wetting contact angle over time change data is presented. The experiments were carried out in a vacuum of $10^{-2} \mathrm{~Pa}$ at temperatures up to $1100{ }^{\circ} \mathrm{C}$. Melts of Al-10 wt\% Ce, La, Nd, Sm; Al -3 wt\% Y; Al-2.5 $w t \% \mathrm{Cu}-3 \mathrm{wt} \%$ Ti and pure aluminum are used. It is shown that up to $1000{ }^{\circ} C$ wetting of the graphite surface by aluminum melts of these compositions does not occur, while the wetting angle is established in the first seconds and practically does not change with time. Above $1000{ }^{\circ} \mathrm{C}$, wetting is improved, with the wetting contact angle of $\mathrm{Al} / 10 \mathrm{wt} \% \mathrm{Ce}$ and $\mathrm{Al} / 10 \mathrm{wt} \% \mathrm{Sm}$ being set in the first seconds and does not change thereafter, and in case of other melts decreases with time. It is most convenient at $1100{ }^{\circ} \mathrm{C}$ that the graphite surface is wetted with Al-10 wt\% La, Al-3 wt\% $\mathrm{Y}$ and Al2.5 wt\% Cu-3 wt\% Ti melts. Aluminum melt and graphite substrate interface structure change data is presented. It is shown that in the interval from 1000 to $1100{ }^{\circ} \mathrm{C}$ interaction between melt and graphite intensifies, there is no significant dissolution of the graphite surface and aluminum carbide is formed. Melts Al / 10 wt\% $\mathrm{Sm}$ and $\mathrm{Al}-2.5 \mathrm{wt} \% \mathrm{Cu}-3 \mathrm{wt} \% \mathrm{Ti}$ interact most active. It is concluded that the activity of the diffusion interaction, in particular the formation of aluminum carbide, is not directly related to the value of the contact angle of wetting. By calculating the Gibbs energy of alumina with REE and $Y$ interaction, it is shown that the reaction can take place in direction of alumina to the metallic state by all elements reduction. The alloying elements used in experiments actually exert various impacts on a superficial tension and properties of an oxide film on the melt surfaces. The most actively superficial tension is changed by elements $\mathrm{Y}, \mathrm{Ti}, \mathrm{Sm}$. Ti and Sm promote active formation of carbide of $\mathrm{Al}_{4} \mathrm{C}_{3}$ aluminum. Lanthanum, obviously, influences a superficial tension a little, but promotes destruction of an oxide film that improves contact with a substrate.
\end{abstract}

Keywords- aluminum melts; graphite; interaction; wetting contact angle
Alibekov Zh. Zh. Institute of Metallurgy and Ore Beneficiation (IMOB) JSC, 050010,

Imbarova A. T. Institute of Metallurgy and Ore Beneficiation (IMOB) JSC, 050010, Republic of Kazakhstan,

Almaty Almaty

\section{INTRODUCTION}

The aluminum-matrix composites reinforced by carbon fiber are perspective constructional materials, and the cast aluminum-matrix composites filled with graphite powders perspective tribotechnical materials. Meanwhile, extremely bad wetting of a surface of carbon a materials aluminum fusion complicates their combination and achievement of properties at the level of settlement. The solution of this problem is reached in two ways: by search of composition of matrix alloys and by drawing technological coverings on the surface of the fillers providing increase in damping of a filler's surface and as a result of his impregnation. Since the drawing the lyophilic coverings significantly increases filler cost, the most optimum is search of the alloys which are characterized by the high moistening ability in relation to carbon materials.

Studies have shown that pure aluminum and aluminum alloys that do not contain carbide-forming elements do not wet the surface of carbon fibers and graphite at temperatures below the formation of $\mathrm{Al}_{4} \mathrm{C}_{3}$ aluminum carbide. For example, alloys of the Al-Cu system wet the surface of carbon fibers only at temperatures above $1420 \mathrm{~K}$, but this process is accompanied by intensive formation of the $\mathrm{Al}_{4} \mathrm{C}_{3}$ phase, which is not permissible. The introduction of carbide-forming elements, in particular titanium, into aluminum, is accompanied by an improvement in wetting, as well as an increase in adhesion performance up to $\sim 1800 \mathrm{~mJ} / \mathrm{m}^{2}$ [1].

Consequently, the conducted tests of the wetting capacity of $\mathrm{Al}-\mathrm{Cu}-\mathrm{Ti}$ melts showed that at a constant copper content of $2.5 \%$ by weight, the wetting power of melts is significantly improved when 2.5-3.5 wt\% Ti. The temperature range of carbon fiber surface wetting by melts of the Al-Cu-Ti system lays in the range of 1090-1170 K. Above $1170 \mathrm{~K}$, the intensive formation of aluminum carbide at the phase boundary of the carbon fiber/alloy was noted. Similar results on the 
effectiveness of carbon fillers surface wetting were obtained for alloys of the Al-Cu-Zr system. The lower values of the carbon fibers surface wetting are characterized by the alloys of the systems Al-Cu-Si, Al-Cu-V, Al-Cu-Mo, Al-Cu-Ta [1].

Meanwhile analysis of binary state diagram (La, Ce, Pr)/C $[2,3]$ shows that they are close on a structure, in particular they form a eutectic with the content of carbon 15-20 at \% and 2-3 steady carbides existing to room temperatures. The most fusible eutectic is formed by $\sim 680{ }^{\circ} \mathrm{C}$ cerium. Lanthanum and praseodymium form an eutectic at 806 and $800{ }^{\circ} \mathrm{C}$. State diagram $\mathrm{Sm} / \mathrm{C}$ and $\mathrm{Nd} / \mathrm{C}$ aren't achieved, however it is possible to assume that their structure will be similar to other lanthanides, but in view of more high temperature of melting of $\mathrm{Sm}$ and $\mathrm{Nd}$ in comparison with $\mathrm{La}, \mathrm{Ce}, \mathrm{Pr}$ it is possible to expect more high temperature of the eutectic which is formed in the $\mathrm{Sm} / \mathrm{C}$ and $\mathrm{Nd} / \mathrm{C}$ systems in the field of small concentration of carbon however in references to it certificates isn't present.

State diagrams analysis ( $\mathrm{La}, \mathrm{Ce}, \mathrm{Pr}, \mathrm{Nd}, \mathrm{Sm}) / \mathrm{Al}$ shows that they are also very close on a structure and are characterized by that in an aluminum corner at $\sim 640{ }^{\circ} \mathrm{C}$ at concentration of $\sim 3$ 8 at the \% of REE is formed an eutectic and there is a number of refractory intermetallic connections. Aluminum with lanthanides doesn't form solid solutions.

The interaction of yttrium with carbon and aluminum is similar to titanium and zirconium; however data on his influence on wetting carbon materials surface in references aren't available.

As rare-earth elements are used as alloying in light alloys of magnesium and aluminum, significantly raising their mechanical characteristics (heat resisting alloy of aluminum from $11 \%$ of a mish metal is known, for example), the prospects of use of alloys of aluminum with individual REE during creation the aluminum-matrix composite materials are available. This makes it necessary to study the influence of parameters of wetting of carbon materials by the aluminum fusions containing rare-earth elements.

\section{EXPERIMENTAL METHOD}

Alloys Al/ 10 wt\% La, Ce, Nd, Sm; Al /3 wt\% Y; Al-2.5 wt $\% \mathrm{Cu}-3 \mathrm{wt} \% \mathrm{Ti}$ for the experiments were prepared in a vacuum induction furnace of aluminum grade $\mathrm{A} 5 \mathrm{~N}$ and $\mathrm{La}, \mathrm{Ce}$, $\mathrm{Nd}, \mathrm{Sm}, \mathrm{Y}, \mathrm{Ti}, \mathrm{Cu}$ with a purity of not less than $99.5 \mathrm{wt} \%$ on the main element. The melting was carried out in a crucible of $\mathrm{Al}_{2} \mathrm{O}_{3}$. To prevent segregation, the melt was poured into a graphite mold.

Experiments on graphite substrates wetting by melts of $\mathrm{Al}$ $/ 10 \mathrm{wt} \% \mathrm{La}, \mathrm{Ce}, \mathrm{Nd}, \mathrm{Sm}$ and $\mathrm{Al} / 3 \mathrm{wt} \% \mathrm{Y}$ were carried out at temperatures up to $1100{ }^{\circ} \mathrm{C}$. For this purpose, video fixing device was used to detect spreading of a melt drop applied to the MPG-7graphite substrate flat ground surface at given temperature under a vacuum of $1 * 10^{-2}-10^{-3} \mathrm{~Pa}$. The temperature deviation during the experiments did not exceed $\pm 10^{\circ} \mathrm{C}$. The volume of the droplet was $36 \pm 3 \mathrm{~mm}^{3}$.

The video records of wetting process obtained during the experiments were decomposed into freeze frames and the contact angle measurement was measured using CorelDraw software with an accuracy at least $\pm 3^{\circ}$. As a result, the dependence of the graphite substrate wetting contact angle on contact time and temperature is obtained. After extraction of samples from the device, the nature of the structure and color changes of the droplet and substrate surface near the droplet was evaluated. Using the methods of scanning electron and optical microscopy and microprobe analysis on the JEOL JXA 8230 analyzer, the structure of the transition zone formed at the interface between melt contact and graphite was studied. To compare data, graphite substrate wetting contact angles with pure aluminum melts and Al-2.5 wt $\%$ Cu-3 wt $\%$.

\section{OUTCOME OF EXPERIMENTS}

Figs. 1 and 2 demonstrate the curve changes in the contact angle of wetting by aluminum by aluminum melt of graphite surface.

As appears from the obtained data, the $\mathrm{Al} / 10 \mathrm{wt} \%$ La melt at temperatures from 700 to $800{ }^{\circ} \mathrm{C}$ does not wet the substrate, the value of the angle practically does not change with time and amounts to $\sim 135^{\circ}$ at $700-750{ }^{\circ} \mathrm{C}$ and $\sim 126^{\circ}$ at $850^{\circ} \mathrm{C}$. At $1050^{\circ} \mathrm{C}$, in the first seconds after melt contact with the substrate, the value of the wetting contact angle drops sharply to $87^{\circ}$. Subsequently, after a slight increase in its value gradually decreases and at 440 seconds is $30^{\circ}$. At temperature increase to $1100^{\circ} \mathrm{C}$, the value of the wetting contact angle at the initial stage is $95^{\circ}$ and after an insignificant decrease after 50 seconds it stabilizes at $85^{\circ}$

The Al/10 wt\% Ce alloy up to $1000^{\circ} \mathrm{C}$ poorly wet the graphite surface. The contact angle of wetting at 700 and $1000^{\circ} \mathrm{C}$ is $135^{\circ}$ and after 50 and 100 seconds it decreases to the level of $126-128^{\circ}$ after which it stabilizes. At $800^{\circ} \mathrm{C}$, the value of the contact angle of wetting up to $300 \mathrm{~s}$ remains practically unchanged and is $133^{\circ}$, and at $900{ }^{\circ} \mathrm{C}$ it does not significantly decrease with time from $136^{\circ}$ for $1 \mathrm{~s}$ to $132^{\circ}$ for $350 \mathrm{~s}$. At $1100^{\circ} \mathrm{C}$, the wetting angle is set $1-2$ seconds at $89^{\circ}$, then reaches a minimum of $86^{\circ}$ at $86^{\circ}$, then stabilizes at $88^{\circ}$.

The $\mathrm{Al} / 10$ wt\% $\mathrm{Nd}$ melt up to $1000{ }^{\circ} \mathrm{C}$ poorly wet the graphite surface. So at $900{ }^{\circ} \mathrm{C}$ the value of the edge angle is stabilized by $140^{\circ}$, while its cyclic changes are observed up to $150 \mathrm{~s}$. At $1000{ }^{\circ} \mathrm{C}$ in the interval from 0 to $360 \mathrm{~s}$, the value of the edge angle decreases from 131 to $122^{\circ}$. At the initial stage, its magnitude is not significantly reduced, then it rises and again decreases. At $1100^{\circ} \mathrm{C}$ there is a gradual decrease in the wetting contact angle value from 138 to $90^{\circ}$.

The contact angle of graphite surface wetting with $\mathrm{Al} / 10$ wt $\% \mathrm{Sm}$ melt at $800^{\circ} \mathrm{C}$ stabilizes after $200 \mathrm{~s}$ and is $\sim 126^{\circ}$. At 1000 and $1100^{\circ} \mathrm{C}$, the change in the edge angle value stops in the first seconds after the melt drop transfer and remains at 104 and $94^{\circ}$, respectively. At the same time not considerable cyclic fluctuations of its size $\pm 2{ }^{\circ} \mathrm{C}$ are observed.

Up to $1000^{\circ} \mathrm{C}$, the graphite surface is poorly wetted by the Al-3 wt\% Y melt, while the temperature of the wetting contact angle does not decrease significantly with increasing temperature, so at $750{ }^{\circ} \mathrm{C}$ it is $\sim 143^{\circ}$, at $800^{\circ} \mathrm{C}-\sim 138^{\circ}$, at $1000^{\circ} \mathrm{C}-\sim 127^{\circ}$. The value of the angle quickly stabilizes and practically does not change with time. A significant 
improvement in the graphite surface wetting is observed with a further increase in temperature. At $1050^{\circ} \mathrm{C}$, the contact angle is $\sim 95^{\circ}$ and practically does not depend on the duration of the contact. At $1075^{\circ} \mathrm{C}$ it decreases from $65^{\circ}$ to $42^{\circ}$ after 80 seconds from the moment of contact with the substrate, and then it grows to $\sim 47^{\circ}$. At $1100^{\circ} \mathrm{C}$, its value is gradually decreasing from $78^{\circ}$ at 1 second to $12^{\circ}$ after 300 seconds.

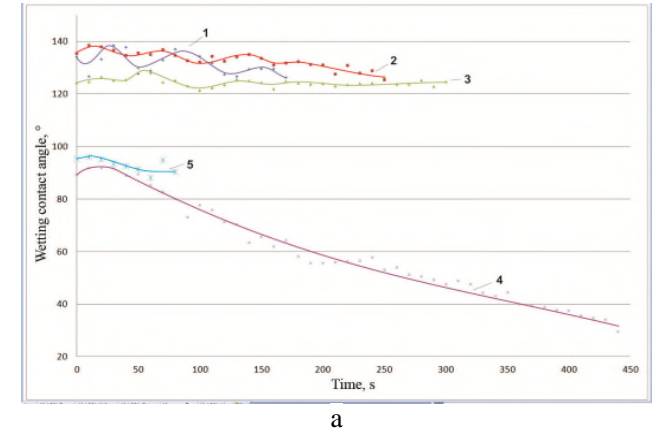

Temperature, ${ }^{\circ} \mathrm{C}: 1$ - 700; 2 - 750; 3 - 850; 4 - 1050; 5 -1100

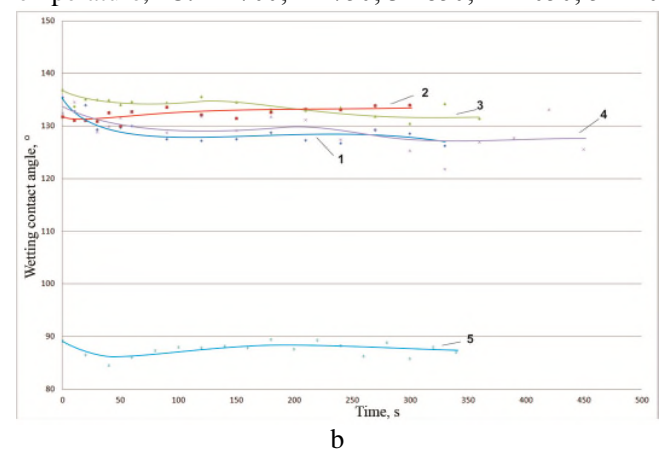

Temperature, ${ }^{\circ} \mathrm{C}: 1$ - 700; 2 - 800; 3 - 900; 4 - 1000; 5 -1100

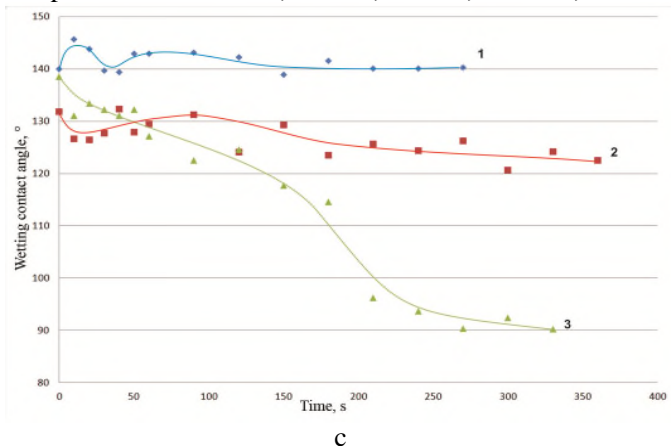

Temperature, ${ }^{\circ} \mathrm{C}: 1$ - 900; 2 - 1000; 3 - 1100

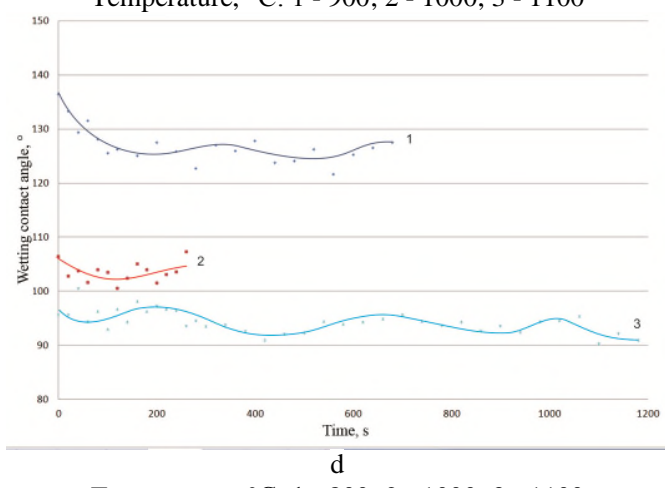

Temperature, ${ }^{\circ} \mathrm{C}: 1$ - 800; 2 - 1000; 3 - 1100

a - Al/10 wt \% La; b- Al/10 wt\% Ce; c - Al /10 wt\% Nd; d -Al/10 wt\% Sm Fig. 1 - Time dependence of the graphite surface wetting contact angle value by an aluminum melt at various temperatures.

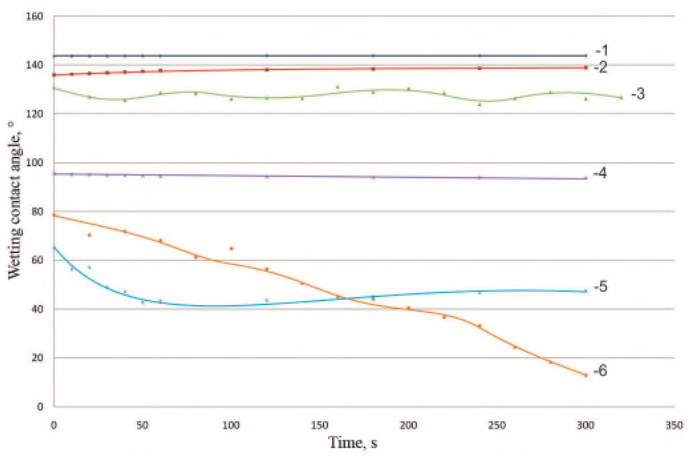

a

Temperature, ${ }^{\circ} \mathrm{C}: 1$ - 750; 2 - 800; 3 - 1000; 4 - 1050; 5 -1075; $6-1100$

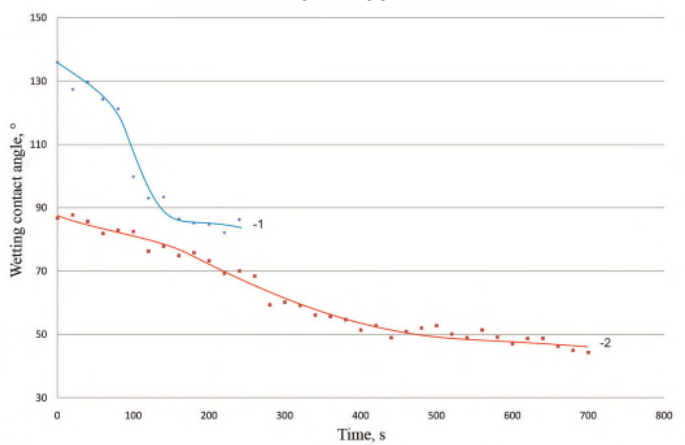

Temperature, ${ }^{\circ} \mathrm{C}: 1-1000 ; 2-1100$

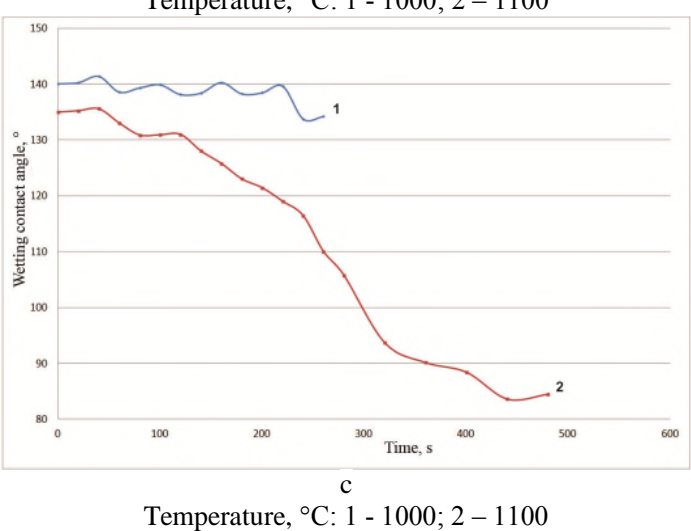

a - Al-3 wt\% Y; b - Al-2.5 wt \% Cu- 3 wt $\%$ Ti; c - pure Al

Fig. 2 - Time dependence of the graphite surface wetting contact angle value by aluminum melt at different temperatures

The marginal angle of graphite wetting with Al-2.5 wt\% $\mathrm{Cu}-3 \mathrm{wt} \% \mathrm{Ti}$ at $1000{ }^{\circ} \mathrm{C}$ in the first seconds of contact with the substrate is $136^{\circ}$ and stabilized through $\sim 170 \mathrm{~s}$ at $85^{\circ}$. At $1100^{\circ} \mathrm{C}$, the wetting contact angle decreases smoothly from $86^{\circ}$ in the first seconds and reaches $44^{\circ}$ after $700 \mathrm{~s}$.

The melt of pure aluminum practically does not wet the graphite surface at $1000^{\circ} \mathrm{C}$, and the value of the contact angle does not decrease significantly in the interval from 0 to $300 \mathrm{~s}$. from $140^{\circ}$ to $135^{\circ}$. At $1100^{\circ} \mathrm{C}$, the value of the edge angle decreases from $135^{\circ}$ to $84^{\circ}$ and stabilizes after 450 seconds from the moment of a melt contact with the substrate.

Investigation of the structure of the transition zone formed between graphite and melts of Al-10 wt $\% \mathrm{La}, \mathrm{Al}-10 \mathrm{wt} \% \mathrm{Ce}$, $\mathrm{Al} / 10 \mathrm{wt} \% \mathrm{Sm}, \mathrm{Al}-10 \mathrm{wt} \% \mathrm{Nd}, \mathrm{Al}-3 \mathrm{wt} \% \mathrm{Y}$ and Al-2.5 wt. \% 
Cu-3 wt \% Ti after their interaction under isothermal holding conditions at temperatures up to $1000{ }^{\circ} \mathrm{C}$ showed that the formation of aluminum, lanthanum, cerium, neodymium and samarium carbides both on the graphite surface and in the volume of the melt does not occur, thus there are no traces of its dissolution. In the interval from 1000 to $1100{ }^{\circ} \mathrm{C}$, the interaction between the melt and graphite intensifies, not significant dissolution of the graphite surface begins, and as follows from the microprobe analysis data, aluminum carbide is formed at the interface. At $1100{ }^{\circ} \mathrm{C}$, the interaction intensity and the width of the carbide layer strongly depend on the alloying element of the aluminum melt. In such a manner, when doping with cerium and lanthanum a discontinuous narrow carbide layer is formed (Fig. 3 a, b). The alloying of aluminum melt with neodymium and yttrium promotes the formation of narrow uniform layers of aluminum carbide (Fig. 3b, 4a). Samarium alloying dramatically intensifies diffusion processes and promotes the active formation of aluminum carbide, while the surface layers of the substrate are cleaved (Fig. 3d). Even more intensely interact with the graphite surface are Al-2.5 wt\% Cu-3 wt\% Ti melts (Fig. 4b). At their contact, aluminum carbide is intensely formed, penetration of fusion on graphite grains borders is observed. The resulting tension causes destruction of the substrate (Fig. 4c).
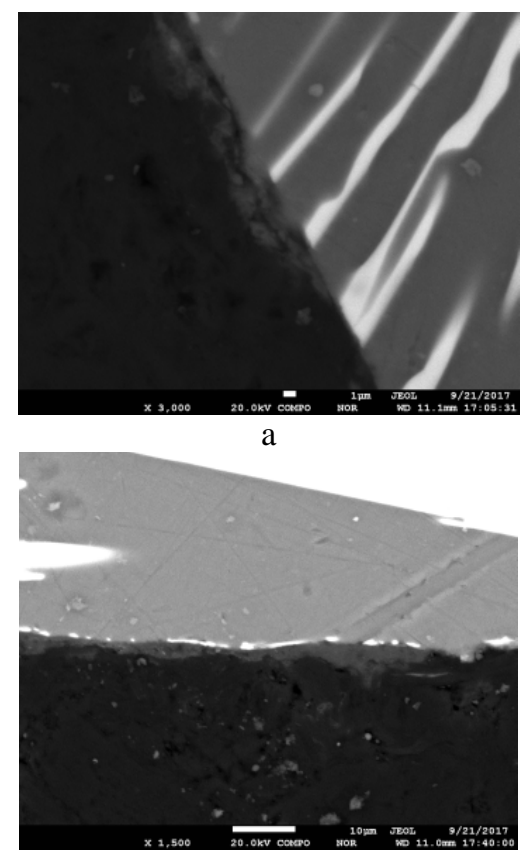

b

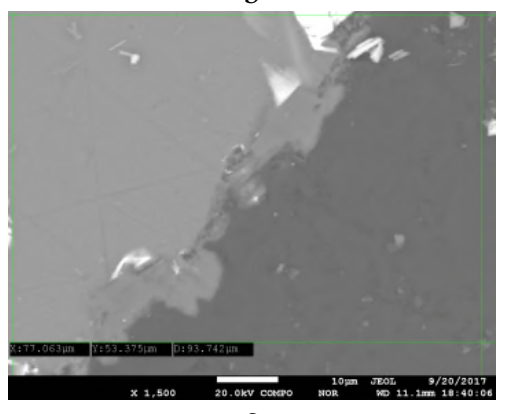

C

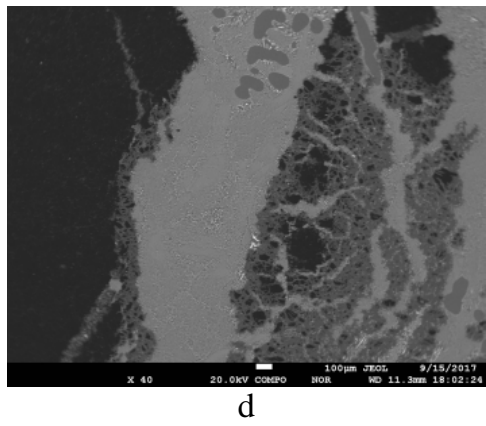

a - Al-10 wt $\%$ La; b - Al-10 wt $\%$ Ce; Al-10 wt $\%$ Nd; d - Al-10 wt $\%$ Sm Fig. 3. Graphite interaction of (dark area) with aluminum melts doped with REE.

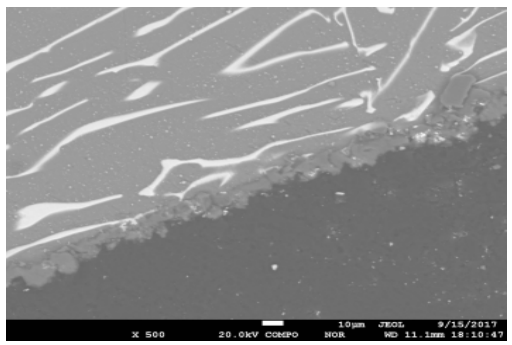

a
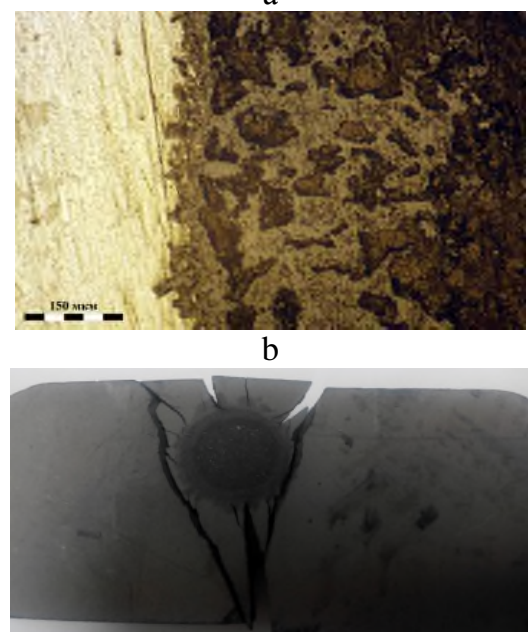

c

a-Al-3 wt $\%$ Y; b-Al-2.5 wt $\%$ Cu- 3 wt $\%$ Ti; c - destruction of the substrate Fig. 4. Graphite interaction with aluminum melts doped with carbide forming elements.

\section{RESULTS EVALUATION}

As appears from the data given above, general regularity of the graphite surface wetting contact angle variation by aluminum alloys doped with $10 \mathrm{wt}$. \% of $\mathrm{La}, \mathrm{Ce}, \mathrm{Nd}, \mathrm{Sm}$ separately is traced. Thus, at temperatures below $1000^{\circ} \mathrm{C}$, graphite is poorly wetted in all cases by aluminum melts doped with lanthanides, while the wetting angle stabilizes in first seconds from the moment of contact and is maintained throughout the experiment with not large fluctuations. The lowest value of the wetting angle is demonstrated by the alloy doped with samarium $-\sim 104^{\circ}$ at $1000^{\circ} \mathrm{C}$. At low temperatures, an aluminum melt doped with $3 \mathrm{wt} \% \mathrm{Y}$ (at $1000^{\circ} \mathrm{C}$ ) likewise demonstrates a poor level of wetting of the graphite surface $\sim 127^{\circ}$.

Above $1000^{\circ} \mathrm{C}$, the wetting of the surface of graphite with aluminum melts is substantially improved. Upon contact 
with a substrate of aluminum melts doped with cerium and samarium, up to $1100^{\circ} \mathrm{C}$, the angle quickly stabilizes at $88^{\circ}$ and $94^{\circ}$, respectively, and does not change with time. In contrast, at $1050^{\circ} \mathrm{C}$, the graphite surface wetting by an alloy doped with a lanthanum is characterized by a smooth decrease in the angle from $87^{\circ}$ to $30^{\circ}$, and at $1100^{\circ} \mathrm{C}$ from $95^{\circ}$ to $85^{\circ}$. Similarly, at $1100^{\circ} \mathrm{C}$, the graphite wetting contact angle decreases smoothly with an aluminum melt doped with neodymium to a value of $\sim 90^{\circ}$.

A smooth decrease in the wetting angle was observed both in contact with graphite melt of Al-2.5 wt $\% \mathrm{Cu}-3 \mathrm{wt} \% \mathrm{Ti}$ at $1000-1100{ }^{\circ} \mathrm{C}$. And with a melt of pure aluminum at $1100{ }^{\circ} \mathrm{C}$. It is known [1], that graphite begins to be wetted by an aluminum melt only after the formation of a layer of aluminum carbide. Since this process is time-dependent, in case of contact angle smooth decrease, it is possible to expect the formation of carbides at the contact boundary, which leads to change in surface properties. In case of wetting contact angle rapid stabilization, the change in melt properties, in particular surface tension and viscosity should play a predominant role in improving the wetting parameters.

Meanwhile, the study of reaction diffusion processes and dissolution at the interface of the graphite substrate contact with aluminum melts shows that the actual wetting of the graphite surface depends little on the aluminum carbide intensity of formation. A vivid example of this is the experiments with aluminum melt doped with samarium. At the same time, aluminum alloying with elements such as lanthanum, titanium, and yttrium contribute to the improvement of graphite surface wetting at high temperatures. In this case, carbide formation upon doping with lanthanum and yttrium is slow, and when doped with titanium it is very active with penetration of the melt along the grain boundaries.

Since the dissolution of the graphite surface does not occur uniformly, this indicates the presence of a separating layer that prevents contact with the melt. This layer can only be a very thin film of aluminum oxide. Probably, with the passage of time the characteristics of this film change two oxidation and destruction processes compete at once. As shown by the thermodynamic calculations carried out using the software package HSC Chemistry 8, the following reactions are possible between the alloying elements and the aluminum oxide film:

$$
\begin{gathered}
\mathrm{Al}_{2} \mathrm{O}_{3}+2 \mathrm{Ce}=2 \mathrm{Al}+\mathrm{Ce}_{2} \mathrm{O}_{3} \Delta \mathrm{G}=-172.7 \mathrm{~kJ} \\
\mathrm{Al}_{2} \mathrm{O}_{3}+2 \mathrm{La}=\mathrm{La}_{2} \mathrm{O}_{3}+2 \mathrm{Al} \Delta \mathrm{G}=-158.7 \mathrm{~kJ} \\
\mathrm{Al}_{2} \mathrm{O}_{3}+\mathrm{La}=\mathrm{LaAlO}_{3}+\mathrm{Al} \Delta \mathrm{G}=-132.4 \mathrm{~kJ} \\
4 \mathrm{Al}_{2} \mathrm{O}_{3}+3 \mathrm{Nd}=\mathrm{Nd}_{3} \mathrm{Al}_{5} \mathrm{O}_{12}+3 \mathrm{Al} \Delta \mathrm{G}=-71.6 \mathrm{~kJ}
\end{gathered}
$$

$$
\mathrm{Al}_{2} \mathrm{O}_{3}+2 \mathrm{Nd}=2 \mathrm{Al}+\mathrm{Nd}_{2} \mathrm{O}_{3} \Delta \mathrm{G}=-178.0 \mathrm{~kJ}
$$

$$
\mathrm{Al}_{2} \mathrm{O}_{3}+2 \mathrm{Sm}=\mathrm{Sm}_{2} \mathrm{O}_{3}+2 \mathrm{Al} \Delta \mathrm{G}=-181.1 \mathrm{~kJ}
$$

$$
\mathrm{Al}_{2} \mathrm{O}_{3}+2 \mathrm{Y}=\mathrm{Y}_{2} \mathrm{O}_{3}+2 \mathrm{Al} \Delta \mathrm{G}=-266.038 \mathrm{~kJ}
$$

$$
4 \mathrm{Al}_{2} \mathrm{O}_{3}+3 \mathrm{Y}=\mathrm{Y}_{3} \mathrm{Al}_{5} \mathrm{O}_{12}+3 \mathrm{Al} \Delta \mathrm{G}=-549.154 \mathrm{~kJ}
$$

It is obvious that the course of these reactions will also be influenced by the vapor pressure of rare-earth elements which significantly differs for them.

\section{CONCLUSION}

Consequently, the process of graphite surface substrates wetting with aluminum melts doped with rare-earth or carbide-forming elements is accompanied by a multitude of physical and chemical processes that exert a finite influence on the parameters of melt flow. New data on the wetting contact angle value dependence and the processes of reaction diffusion on the temperature and the content of the alloying element developing at the contact boundary in the graphite / aluminum melt system are obtained. These data indicate the prospects for the use of aluminum alloys doped with lanthanum, yttrium, as matrix materials for the production of metal matrix composites reinforced with discrete carbon particles or carbon fibers.

The work was carried out within the framework of the grant of the Ministry of Education and Science of the Republic of Kazakhstan No.0676/GF4 "Development of new cast aluminum-composite materials for tribotechnical purposes and improvement of technology and equipment for their production".

During the work performance, the equipment of the National Scientific Laboratory of Collective Use in the priority area "Technologies for the Hydrocarbon and Mining and Metallurgical Sectors and Related Service Industries" was used.

\section{REFERENCES}

[1] V.I. Kostikov and A.N. Varenkov, Composite materials based on aluminum alloys reinforced with carbon fibers. - Moscow: Intermet Engineering. 2000, pp. 445.

[2] K.A. Gschneidner and F.W. Calderwood Jr. "The C-La (CarbonLanthanum) System" Bull. Alloy Phase Chart. vol. 7. no. 5. pp. 446-449, 1986.

[3] K.A. Gschneidner and F.W. Calderwood Jr. "The C-Ce (CarbonCerium) System” Bull. Alloy Phase Chart. vol. 7. no. 5, pp. 437-438, 1986 